\title{
Stigmatizing Attitudes about Mental Illness and Allocation of Resources to Mental Health Services
}

\author{
Patrick W. Corrigan \\ Amy C. Watson \\ Amy C. Warpinski \\ Gabriela Gracia
}

\begin{abstract}
This study tests a social psychological model (Skitka \& Tetlock, 1992). Journal of Experimental Social Psychology, 28, 491-522; [1993]. Journal of Personality \& Social Psychology, 65, 1205-1223 stating that policy maker decisions regarding the allocation of resources to mental health services are influenced by their attitudes towards people with mental illness and treatment efficacy. Fifty four individuals participated in a larger study of education about mental health stigma. Participants completed various measures of resource allocation preferences for mandated treatment and rehabilitation services, attributions about people with mental illness, and factors that influence allocation preferences including perceived treatment efficacy. Results showed significant attitudinal correlates with resource allocation preferences for mandated treatment, but no correlates to rehabilitation services. In particular, people who pity people with mental illness as well as those that endorse coercive and segregated treatments, were more likely to rate resource allocation to mandated care as important. Perceived treatment efficacy was also positively associated with resource allocation preferences for mandated treatment. A separate behavioral measure that involved donating money to NAMI was found to be inversely associated with blaming people for their mental illness and not being willing to help them. Implications of these findings on strategies that seek to increase resources for mental health programs are discussed.
\end{abstract}

KEYWORDS: stigma; mental illness; mental health services.

All the authors are affiliated with University of Chicago Centre for Psychiatric Address correspondence to Patrick Corrigan, University of Chicago Center for Psychiatric 7230 Arbor Drive, Tinley Park, IL 60477; e-mail: p-corrigan@uchicago.edu 
Although stigmatizing attitudes about persons with mental illness among members of the general population can lead to harmful and discriminatory behaviors, the consequences of stigma among members of key groups such as employers, landlords, and primary care physicians can be especially poignant in the lives of people with mental illness (Corrigan, in press). For example, legislators who endorse prejudice about people with mental illness can block funding for mental health services that may promote independent living and recovery goals. We recently applied Skitka and Tetlock's (Skitka, 1990; Skitka \& Tetlock, 1992, 1993) resource allocation model to explain how mental illness stigma affects the resource allocation decisions made by government officials (Corrigan \& Watson, 2003). The study presented in this paper provides an empirical test of some of the assumptions in the earlier article.

Skitka and Tetlock $(1992,1993)$ argued that legislators and other government officials play a major role in human services through the decisions they make about the allocation of public resources. Skitka and Tetlock identified two sets of social-cognitive factors that may influence a person's preferences for resource allocation to individual programs: attitudes about the group of people served by those programs and attitudes about the effectiveness of services comprising individual programs. We applied their social-psychological model to understand resource allocation for mental health services (Corrigan \& Watson, 2003). In this study, we hypothesize that attitudes about people with mental illness and beliefs about treatment efficacy will be associated with resource allocation preferences.

Substantial work by our group (Corrigan, Markowitz, Watson, Rowan, \& Kubiak, in press; Corrigan, et al., 2002) and others (Farina, 1998; Link \& Phelan, 2001; Pescosolido, Monahan, Link, Stueve, \& Kikuzawa, 1999; Wahl, 1999) have identified a variety of stigmatizing attitudes about people with mental illness that might affect resource allocation. Two models seem especially relevant. Based on Weiner's (1995) attribution theory, we have shown that members of the general public who view people with mental illness as responsible for their symptoms and disabilities are likely to react angrily and behave in a punitive manner; i.e., endorse mental health services that are coercive and segregated from the community. Conversely, members of the general public who view people with mental illness as victimized by their symptoms (i.e., not to blame) are likely to react with pity and offer help; e.g., rehabilitation services. The second model of stigmatizing attitudes is based on Link's 
theory about dangerousness (Link, Andrews, \& Cullen, 1992; Link, Monahan, Stueve, \& Cullen, 1999; Link, Phelan, Bresnahan, Stueve, $\&$ Pescosolido, 1999). Namely, members of the general public who view people with mental illness as dangerous are likely to fear and avoid them; e.g., not hire or rent apartments to them. We expect resource allocation preferences, especially for mandated treatments, to be associated with perceived danger and fear.

\section{METHODS}

Skitka and Tetlock (1992, 1993) used samples of college students to test their theory about resource allocation based on the rationale that policy makers will demonstrate the same basic attitude-affect-behavior links shown in analog samples. Research participants for our study were drawn from the at-large student body of a local community college. We have used community college students in prior research because they tend to be more demographically representative of the population as a whole than college sophomores from 4-year universities (Corrigan et al., 2001b; Corrigan et al., 1999; Corrigan et al., 2002; Reinke, Corrigan, \& Leonhard, in press). Data for this paper was obtained from a larger study on the impact of anti-stigma programs (Corrigan, Watson, Warpinski, \& Gracia, MS submitted to Psychiatric Services). One hundred and fifty nine individuals in the larger study were randomly assigned to one of three conditions: education about stigma, education about violence, or a no-information control group. The analyses reported here are restricted to the 54 individuals in the control group who received no information about mental illness or mental health services. Instead, they received a presentation about technology and hobbies. They completed measures at post-test and one week follow-up.

This sample had an average age of 25.7 years $(\mathrm{SD}=9.5)$ and was $67.3 \%$ female. In terms of marital status, $70.9 \%$ were single, $20.0 \%$ were married, $1.8 \%$ were separated, and $5.5 \%$ were divorced. The sample was $49.1 \%$ European American, $43.6 \%$ African American, 3.6\% Latino, and 3.6\% other including Asian and Native American; this diversity is important because other investigations have found ethnicity predicts prejudice against mental illness (Corrigan, Edwards, Green, Diwan, \& Penn, 2001a). In terms of education, $7.3 \%$ completed high school, $87.3 \%$ received some college, and $5.5 \%$ had a college degree. For household income, 20.0\% earned less than $\$ 20,000,32.7 \%$ earned $\$ 20,000-40,000,16.4 \%$ earned $\$ 40,000-60,000,12.7 \%$ earned $\$ 60,000-80,000$ and $16.7 \%$ earned more than $\$ 80,000$.

\section{Measures}

Research participants completed measures that assess resource allocation preferences for various mental health services, attitudinal preferences about treatment and resource allocation, and attitudes about people with mental illness.

Resource Allocation Measure. In their social-psychological research, Skitka and Tetlock $(1992,1993)$ showed that attitudes about needy groups (e.g., woman needing food support for their children; people with AIDS) are associated with how policy makers allocate funds to corresponding programs (e.g., community food pantries and AZT subsidy clinics). Corrigan and Watson (2003) extended this model to 
understanding how attitudes about mental illness influence legislator's allocation of resources to mental health services. In their original research, Skitka and Tetlock (1992) developed a resource allocation task in which research participants were asked to divide a million dollar budget among eight human service agencies. The relative amount of money allocated to specific agencies was an index of resource allocation for that type of program. In a pilot study, we attempted to extend this strategy in terms of allocating a million dollar budget across eight mental health services. Unfortunately, research participants had difficulty understanding the task and could not complete it accurately (e.g., the sum of monies allocated to the eight mental health services would exceed the one million dollar allowance).

After consultation with Skitka, we revised the measure for this study. Research participants were told to rank the importance of allocating state monies to each of four mental health services on a nine-point Likert Scale $(9=$ extremely important). The four mental health services in the measure were selected via a pilot where 17 students and staff members at a mental health agency rated eight mental health services on scales representing coercion, punishment, empowerment, and independence. In order to pick services that reflect the poles of these values, we selected the two that were scored highest on coercion and punishment plus the two that were scored highest on empowerment and independence for the final measure. Items from the Resource Allocation Measure were combined to yield two subscale scores: importance of funding Rehabilitation Services (like vocational rehabilitation and psychosocial rehabilitation services) and importance of funding Mandated Treatments (like involuntary hospitalization and outpatient commitment). Previous analyses showed that the two items comprising the Rehabilitation Services Subscale were highly correlated $(r=0.61)$ as were the two items in the Mandated Treatment Scale ( $r=0.49)$ (Corrigan et al., submitted manuscript). We were concerned that completing this measure might yield a demand effect at pre-test of our original study on education and stigma. Hence, we only administered the Resource Allocation Measure at post-test and follow-up. The relationship between post-test and follow-up scores represents test-retest reliability for the control group. Remaining analyses were conducted on post-test Resource Allocation Measure and the post-test measures discussed below.

NAMI Donation. In addition to statements about behavioral decisions, we wanted to assess direct behavior related to allocating resources and helping persons with serious mental illness. In an earlier study, we developed and validated the NAMI donation task (Corrigan et al., 2002). Individuals participating in the study were reimbursed $\$ 10$ at post-test for their effort. After completing all post-tests, research participants were instructed in a brief note that they could donate any or all of this money to the National Alliance for the Mentally Ill of the Southwest Suburbs. Participants were provided a paragraph-long description of the advocacy and education efforts of NAMI. Research participants were given a receipt on which they could specify the number of dollars they wished to donate. Total donated dollars is reported here. Research by our group has shown this task to be a significantly sensitive measure to the impact of education and other anti-stigma programs (Corrigan et al., 2002).

Attribution Questionnaire. In earlier work, we outlined a nine factor path model for explaining the relationship between public attitudes, corresponding affect, and resulting decisions related to people with mental illness; test-retest and confirmatory factor analysis have demonstrated the reliability and validity of this model (Corrigan et al., in press; Corrigan et al., 2002). The Attribution Questionnaire (AQ) is the measure used to test this model. When completing the $\mathrm{AQ}$, research participants are 
presented a very short and neutral statement about "Harry" who works as a clerk in a law firm and has been hospitalized for schizophrenia. Other work by our group shows asking participants to respond to a specific person with mental illness, rather than to people with mental illness in general, leads to a more sensitive measure of attitudes that better corresponds with concurrent validators (Corrigan et al., 1999).

Research participants then answer $27 \mathrm{AQ}$ items about their response to Harry on a 9 point Likert Scale; e.g., "Harry would terrify me" (9 = very much). Based on our earlier work, nine factor scores were obtained from the AQ to answer the questions of this study. (1) Responsibility; e.g., "Harry is to blame for his illness."; (2) Pity; e.g., "I would have sympathy for Harry."; (3) Anger; "Harry would make me angry."; (4) Dangerousness; e.g., "I would feel unsafe around Harry."; (5) Fear: e.g., "Harry would terrify me."; (6) Avoidance (reverse scored); e.g., "If I were an employer, I would interview Harry for a job."; (7) Coercion; e.g., "If I were in charge of Harry's treatment, I would require him to take his medication."; (8) Segregation; e.g., "I think it would be best for Harry's community if he were put away in a psychiatric hospital."; (9) No Help; "How likely is it that you would help Harry?"

Allocation Preference Questionnaire. Skitka and Tetlock (1992, 1993) measured public attitudes about human services using a six-item measure representing allocation preferences. We rewrote the scale so that it applied to mental health services. The items represented medical need, equal opportunity (selection for services should be based solely on chance), time on waiting list, treatment efficacy, highest bidder (services should go first to people who can pay for them) and community contribution (services should be provided to people who provide a contribution to their community). Research participants rated items on a 17 -point appropriateness scale $(-8=$ extremely inappropriate, $+8=$ extremely appropriate).

\section{RESULTS}

The mean and standard deviation of the subscale and item scores are summarized in Table 1. Results of planned, repeated measures ANOVAs showed two interesting findings. First, no difference was found for the two subscales of the Resource Allocation Questionnaire ( $F$ $(1,53)=.98$, n.s. $)$. In other words, participants did not seem to significantly distinguish their rating of the importance of allocating resources to mandated treatment and rehabilitation services. Second, significant differences among the six subscales of the Allocation Preference Questionnaire $(\mathrm{F}(5,49)=38.39, p<.0001)$ were found. Post-hoc comparisons suggest the six reasons for allocation preference can be grouped into three significantly different $(p<.05)$ sets. Medical need was rated as most appropriate for deciding allocations. Treatment efficacy and time on waiting list were rated as relatively neutral in terms of allocation preference. Equal opportunity, highest bidder, and person's contribution to the community were all rated as relatively inappropriate in terms of resource allocation. 
TABLE 1

Mean and Standard Deviations of Subscale Scores for the Attribution Questionnaire, Service Allocation Questionnaire, Allocation Preference Questionnaire, and the NAMI Donation

\begin{tabular}{lccc}
\hline Scale (subscale) & Mean & $\begin{array}{c}\text { Standard } \\
\text { deviation }\end{array}$ & $\begin{array}{l}\text { Test-retest } \\
\text { reliability }\end{array}$ \\
\hline Resource Allocation & & & \\
Questionnaire & & & \\
$\quad$ Mandated treatment & 14.2 & 3.5 & .55 \\
$\quad$ Rehabilitation services & 14.4 & 2.7 & .57 \\
NAMI donation & $\$ 2.07$ & $\$ 3.78$ & \\
& & & \\
Attribution Questionnaire & & & \\
Responsibility & 8.2 & 4.4 & .55 \\
Pity & 18.8 & 5.6 & .82 \\
Anger & 8.3 & 4.1 & .64 \\
Danger & 12.0 & 5.2 & .87 \\
Fear & 10.2 & 5.6 & .86 \\
No Help & 9.7 & 5.7 & .80 \\
Coercion & 17.1 & 4.1 & .56 \\
Segregation & 9.8 & 5.3 & .75 \\
Avoidance & 14.5 & 6.5 & .78 \\
Allocation Preference Questionnaire & & & \\
Medical need & 4.3 & 4.9 & .36 \\
Equal opportunity & -4.0 & 5.2 & .36 \\
Time on waiting list & 1.3 & 5.1 & -.05 \\
Treatment efficacy & 0.1 & 5.5 & .46 \\
Highest bidder & -6.2 & 4.3 & .56 \\
Community contribution & -6.1 & 4.0 & .22 \\
\hline
\end{tabular}

The right hand column of Table 1 lists the test-retest reliabilities of the subscales and items used in this study. Note that test-retest reliability for the nine subscales of the Attribution Questionnaire were fairly robust as were the two subscales of the Resource Allocation Questionnaire. The range of correlation indices for the six items of the Allocation Preference Scale showed some items with fair reliability (e.g., treatment efficacy and highest bidder) while the remaining had poor test-retest reliabilities. 
Table 2 lists the Pearson Product Moment Correlations between the three proxies of resource allocation (Ratings of importance for funding Rehabilitation Services and Mandated Treatment and the amount of money actually donated to NAMI) and measures of attributions about people with mental illness and factors that affect allocation preferences. Note that indices are flagged as significant in Table 2 if they meet the .05 and/or the Bonferroni criteria.

Results show that none of the subscale or item scores were significantly associated with the perceived importance of allocating resources for Rehabilitation Services. Perceived importance of Mandated Treatment was significantly associated with Coercion and Segregation on the

TABLE 2

Pearson Product Moment Correlations Among Service Allocation Items and Measures of Attitudes

\begin{tabular}{|c|c|c|c|}
\hline Scale (subscale) & $\begin{array}{c}\text { Rehabiliation } \\
\text { services }\end{array}$ & $\begin{array}{l}\text { Mandated } \\
\text { treatment }\end{array}$ & $\begin{array}{c}\text { NAMI } \\
\text { donation }\end{array}$ \\
\hline \multicolumn{4}{|l|}{ Attribution Questionnaire } \\
\hline Responsibility & .18 & -.13 & $-.20^{*}$ \\
\hline Pity & .02 & $.28^{*}$ & $.19^{* *}$ \\
\hline Anger & -.06 & -.03 & -.16 \\
\hline Danger & -.02 & .16 & -.11 \\
\hline Fear & -.08 & $.20^{* *}$ & -.15 \\
\hline No Help & -.06 & -.09 & $-.27^{*}$ \\
\hline Coercion & .04 & $.41 * * *$ & -.10 \\
\hline Segregation & .12 & $.34 * * * *$ & .03 \\
\hline Avoidance & -.03 & .12 & -.04 \\
\hline \multicolumn{4}{|l|}{ Allocation Preference } \\
\hline \multicolumn{4}{|l|}{ Questionnaire } \\
\hline Medical need & .05 & -.13 & .02 \\
\hline Equal opportunity & -.12 & -.06 & -.09 \\
\hline Time on waiting list & .10 & -.03 & .16 \\
\hline Treatment efficacy & .01 & $.35 * * *$ & .10 \\
\hline Highest bidder & .15 & .11 & $-.18^{* * *}$ \\
\hline Community contribution & .08 & .10 & -.04 \\
\hline$R^{2}$ & .23 & .37 & .32 \\
\hline
\end{tabular}


Attribution Questionnaire. This makes sense; research participants who believe that services should be coercive and segregated from the community are likely to endorse more resources for mandated care. Interestingly, importance of resources for mandated treatment was positively associated with two of the subscales representing affective response to people with mental illness-pity and fear-though the association with fear was only a nonsignificant trend. Importance of resources for Mandated Treatment was also associated with perceived treatment efficacy; i.e., research participants who perceived treatment as more efficacious were more likely to rate resources for mandated treatment as important.

Table 2 also shows that NAMI donations were significantly associated with some of the attribution and allocation preference subscales/ items. Significant and inverse associations were found between NAMI donations and Attribution Questionnaire Subscales representing Responsibility and No Help. In addition, nonsignificant trends described the relationship between NAMI donations and Pity on the Attribution Questionnaire as well as the highest bidder preference on the Allocation Preference Questionnaire.

\section{DISCUSSION}

The purpose of this study was to test a model of allocating resources to mental health services and its relationship to attitudes about people with mental illness and beliefs about treatment efficacy. Two generic sets of mental health services were the focus of this study; mandated treatment and rehabilitation services. Results were mixed; they showed that attitudes were significantly associated with preferences for allocating resources to mandated treatment. No significant associations were found between attitudes and preferences for allocating resources to rehabilitation services. The perceived importance of mandated treatment was significantly associated with stigmatizing attitudes about mental illness that support coercive treatments and segregated institutions. In some ways, these findings might be viewed as validating the resource allocation measure because mandated treatments are often considered synonymous with coercion and segregation.

Allocation of resources to mandated treatment was also significantly associated with pity for people with mental illness. Research participants who reported greater pity for people with mental illness endorsed more mandated treatment. This is consistent with authoritarian 
notions about people with mental illness (Brockington, Hall, Levings, \& Murphy, 1993; Taylor \& Dear, 1980). Namely, the mental health system should mandate some services for people with mental illness because of parental concern. Finally, views about treatment efficacy were associated with mandated treatment preference. This is consistent with Skitka and Tetlock's work $(1992,1993)$.

Donation to NAMI was added as a behavioral proxy of resource allocation. Results showed that actual monetary donations to NAMI were inversely correlated to the No Help and responsibility subscales of the Attribution Questionnaire. The inverse association with No Help validates the NAMI donation task; namely, research participants who are willing to help people with mental illness may do so with monetary donations to advocacy groups like NAMI. Findings also supported our hypothesis; namely, research participants who view people with mental illness as responsible for their symptoms and disabilities are less likely to actually give money to services that ostensibly support these people.

A difficult question to address is why attitudes were not found to be significantly associated with resource allocation to rehabilitation services. No psychometric properties of the Rehabilitation Services Subscale greatly distinguish it from the Mandated Treatment Subscale. They had similar test-retest reliabilities though the range and variance of scores for the Rehabilitation Services Subscale was a bit more constricted than the Mandated Treatment Subscale. Nor does there seem to be a readily apparent theoretical reason why attitudes about people with mental illness and beliefs about treatment would be associated with allocation of resources to mandated treatments but not rehabilitation services. Perhaps other attitudes about people with mental illness not included in this study might predict resource allocation to these services. Future research needs to consider this association more completely.

There were several limitations to this study that need to be addressed in follow-up research. First, the small sample size may have underpowered some of the analyses thereby obscuring possibly significant results. Subsequent research with larger samples is needed. Second, the study used an analog group (community college students) to support some of our hypotheses about the link between attitudes and resource allocation. As we have argued elsewhere (Corrigan, in press), the institutional exigencies placed on people acting within certain social roles (e.g., a state legislator or mental health policy maker) will likely influence their attitudes and behaviors in a manner distinct from the general population. Hence, 
research conducted on analog groups needs to be repeated on samples drawn from the more specific population of interest. Third, measures used in this research were proxies of actual decision making about resource allocation. Future research should include measures that represent how legislators have actually voted on individual bills related to resources for mental health services.

Findings from studies like these have implications for better understanding the resource allocation process and for devising advocacy-based strategies that will influence this process. They echo conclusions of our earlier paper (Corrigan \& Watson, 2003); namely, policy makers are psychological beings affected by the same attitude behavior links that describe much human functioning. Hence, understanding the attitudes and emotions that influence their allocation decisions provides valuable information in terms of structuring advocacy efforts that will yield mental health friendly decisions.

\section{REFERENCES}

Brockington, I., F., Hall, P., Levings, \& J., Murphy, C. (1993). The community's tolerance of the mentally ill. British Journal of Psychiatry, 162, 93-99.

Corrigan, P. W. (in press). Target-specific stigma change: A strategy for impacting mental illness stigma. Psychiatric Rehabilitation Journal.

Corrigan, P. W., Edwards, A. B., Green, A., Diwan, S. L., \& Penn, D. L. (2001a). Prejudice, social distance, and familiarity with mental illness. Schizophrenia Bulletin, 27(2), 219-225.

Corrigan, P.W., Markowitz, F.E., Watson, A.C., Rowan, D., \& Kubiak, M.A. (2003). An attribution model of public discrimination towards persons with mental illness. Journal of Health \& Social Behavior, 44(2), 162-179.

Corrigan, P. W., River, L. P., Lundin, R., Wasowski, K. U., Campion, J., Mathisen, J., et al. (1999). Predictors of participation in campaigns against mental illness stigma. Journal of Nervous \& Mental Disease, 187, 378-380.

Corrigan, P. W., River, L., Lundin, R. K., Penn, D. L., Uphoff-Wasowski, K., Campion, J., et al. (2001b). Three strategies for changing attributions about severe mental illness. Schizophrenia Bulletin, 27(2), 187-195.

Corrigan, P. W., Rowan, D., Green, A., Lundin, R., River, P., Uphoff-Wasowski, K., et al. (2002). Challenging two mental illness stigmas: Personal responsibility and dangerousness. Schizophrenia Bulletin, 28, 293-310.

Corrigan, P. \& Watson, A. (2003). What factors influence how policy makers distribute resources to mental health services. Psychiatric Services, 54, 501-507.

Farina, A. (1998). Stigma. In K. T. Mueser \& N. Tarrier (Eds.), Handbook of social functioning in schizophrenia (pp. 247-279). Needham Heights, MA: Allyn \& Bacon, Inc.

Link, B., Andrews, H., \& Cullen, F. (1992). The violent and illegal behavior of mental patients reconsidered. American Sociological Review, 57, 275-292.

Link, B. G., Monahan, J., Stueve, A., \& Cullen, F. T. (1999). Real in their consequences: A sociological approach to understanding the association between psychotic symptoms and violence. American Sociological Review, 64(2), 316-332.

Link, B. G., Phelan, J. C., Bresnahan, M., Stueve, A., \& Pescosolido, B. A. (1999). Public conceptions of mental illness: Labels, causes, dangerousness, and social distance. American Journal of Public Health, 89(9), 1328-1333. 
Link, B. \& Phelan, J. (2001). Conceptualizing stigma. Annual Review of Sociology, 27, 363-385. Pescosolido, B. A., Monahan, J., Link, B. G., Stueve, A., \& Kikuzawa, S. (1999). The public's view of the competence, dangerousness, and need for legal coercion of persons with mental health problems. American Journal of Public Health, 89(9), 1339-1345.

Reinke, R., Corrigan, P., \& Leonhard, C. (in press). Examining media's use of contact in the stigma of mental illness. Journal of Nervous \& Mental Disease.

Skitka, L. (1990) Health care allocation priorities: Locus-of-responsibility, scarcity, and cognitive style. Dissertation Abstracts International, 50, 4820-4821.

Skitka, L. \& Tetlock, P. (1992). Allocating scarce resources: A contingency model of distributive justice. Journal of Experimental Social Psychology, 28, 491-522.

Skitka, L. \& Tetlock, P. (1993). Providing public assistance: Cognitive and motivational processes underlying liberal and conservative policy preferences. Journal of Personality \& Social psychology, 65, 1205-1223.

Taylor, S. M. \& Dear, M. J. (1980). Scaling community attitudes toward the mentally ill. Schizophrenia Bulletin, 7, 225-240.

Wahl, O. (1999). Mental health consumers' experience of stigma. Schizophrenia Bulletin, 25, 467-478.

Weiner, B. (1995). Judgments of responsibility: A foundation for a theory of social conduct. New York, NY: The Guilford Press. 